\title{
A new Web-based medical tool for assessment and prevention of comprehensive cardiovascular risk
}

This article was published in the following Dove Press journal:

Therapeutics and Clinical Risk Management

22 February 201I

Number of times this article has been viewed

\section{Daniele Franchi ${ }^{1,2}$ \\ Davide Cini' \\ Giorgio lervasi'}

'Istituto di Fisiologia Clinica, CNR, Pisa, Italy; ${ }^{2}$ Dipartimento di Oncologia, dei Trapianti e delle Nuove Tecnologie in Medicina, Università di Pisa, Pisa, Italy
Correspondence: Daniele Franchi Clinical Physiology Institute, C.N.R. (National Research Council),

56124 Pisa, Italy

Tel +39-050-3I52285

$\mathrm{Fax}+39-050-3152166$

Email franchid@ifc.cnr.it
Background: Multifactor cardiovascular disease is the leading cause of death; besides well-known cardiovascular risk factors, several emerging factors such as mental stress, diet type, and physical inactivity, have been associated to cardiovascular disease. To date, preventive strategies are based on the concept of absolute risk calculated by different algorithms and scoring systems. However, in general practice the patient's data collection represents a critical issue.

Design: A new multipurpose computer-based program has been developed in order to:1) easily calculate and compare the absolute cardiovascular risk by the Framingham, Procam, and Progetto Cuore algorithms; 2) to design a web-based computerized tool for prospective collection of structured data; 3 ) to support the doctor in the decision-making process for patients at risk according to recent international guidelines.

Methods: During a medical consultation the doctor utilizes a common computer connected by Internet to a medical server where all the patient's data and software reside. The program evaluates absolute and relative cardiovascular risk factors, personalized patient's goals, and multiparametric trends, monitors critical parameter values, and generates an automated medical report.

Results: In a pilot study on 294 patients ( $47 \%$ males; mean age $60 \pm 12$ years [ \pm SD]) the global time to collect data at first consultation was $13 \pm 11$ minutes which declined to $8 \pm 7$ minutes at the subsequent consultation. In $48.2 \%$ of cases the program revealed 2 or more primary risk factor parameters outside guideline indications and gave specific clinical suggestions to return altered parameters to target values.

Conclusion: The web-based system proposed here may represent a feasible and flexible tool for clinical management of patients at risk of cardiovascular disease and for epidemiological research.

Keywords: internet, informatics, cardiovascular risk, evidence-based practice, medical consultation, decision support, clinical information systems

\section{Introduction}

Cardiovascular (CV) disease, and in particular coronary artery disease (CAD), is a multifactor syndrome that represents the leading cause of death, accounting for over 15 million deaths worldwide each year. ${ }^{1,2}$ In addition to the well-known nonmodifiable risk factors for $\mathrm{CV}$ disease, such as sex (ie, male gender), age, and genetic predisposition ${ }^{3}$ there are a number of modifiable factors which could - to some extent - be prevented. ${ }^{4}$

The major modifiable risk factors for $\mathrm{CV}$ disease are smoking, hypertension, diabetes, and hypercholesterolemia. ${ }^{1,2}$

The impact of these factors in the development and worsening of CAD has been unequivocally demonstrated by international controlled epidemiologic studies and 
large pharmaceutical trials. ${ }^{1,2}$ Over the years, research has identified over 200 additional risk factors (eg, bio-humoral, lifestyle behaviors, and psychosocial factors) associated with $\mathrm{CAD},{ }^{5-13}$ but what has not yet been extensively investigated is the true clinical relevance for the majority of them, especially compared with that of conventional factors.

A number of algorithms and scoring systems have been developed to calculate absolute risk, ranging from simpleto-use scores to complicated computer-based algorithms, all of which are based, however, on just a few risk parameters. A fundamental problem for all risk algorithms is that they make significantly different assumptions about the nature of mathematical relationships that exist between the individual variables. $^{14,15}$

Physicians often underestimate their patient's CV risk. ${ }^{16}$ Only $13 \%$ of primary care physicians are said to use a risk chart to assess patient's risk. In another study it was not possible to calculate a CV risk using guidelines for $43 \%$ of patients because of deficiency of information. ${ }^{17}$ The likely explanations are that very often the risk computation is performed after and out of the medical consultation, and the recording is paper-based and not computerized. Moreover, recent studies have shown that in general practice it has not been possible to calculate $\mathrm{CV}$ risk in $50 \%$ of patients because of low levels of information recordings. ${ }^{3}$ Even for well-known CV risk factors (eg, blood pressure), less than $25 \%$ of patients with hypertension have adequate blood pressure control due to lack of adherence to international guidelines, ${ }^{14}$ and less than $10 \%$ have both blood pressure and cholesterol controlled. ${ }^{15,17}$

The aim of the paper is to present a new computer-based program, developed by the National Council Research Institute of Clinical Physiology of Pisa, with the following goals: 1) to calculate easily and compare the absolute risk using the two major risk score algorithms that exist today and by using the Italian Progetto Cuore risk chart; 2) to design a web-based computerized tool for long-term and prospective collection of structured data utilized for developing a reliable algorithm able to identify correctly individuals at risk; 3 ) to support the doctor in the decision making process for patients at risk according to the recent international guidelines to improve the care of patients with CAD.

\section{Materials and methods}

\section{General aspects of the computer-based program}

We developed the software VIRC (Valutazione Integrata del Rischio Cardiovascolare, ie, Integrated Evaluation of Cardiovascular Risk) for use free of charge, without commercial license, by the medical community anywhere in the world. New users can register with their personal identification, medical institution, and title by visiting the web server homepage (https://virc.ifc.cnr.it). A personal account is generated and communicated via email.

The computer-based program enables physicians to use their computer during patient appointments to collect in a systematic way the data on the patient's clinical status.

Development of the project included the following steps: 1) definition of dataset; 2 ) execution of a pilot study on a limited series of patients $(n=294) ; 3)$ territorial extension of the pilot study with involvement of 20 practitioners to obtain a relatively large sample of patients enrolled ( $n=3000$ in current year); 4) adjustment of the model data, if necessary, on the basis of indications raised by pilot studies; 5) extension of the program with enrollment of at least 10,000 patients, a number considered appropriate for preliminary epidemiological studies, in 18 months. The first two steps have now been completed and step 3 is now in progress in the Tuscan territory. Next year a final report is expected on the Tuscany study, and if the results are positive, an international trial will be set up.

\section{Dataset}

The medical dataset was created by a research group of specialists (cardiologists, internal medicine specialists, endocrinologists, and others) on the basis of the importance of each CVD factor as stated in international medical literature. Two international guidelines were selected: 1) Pocket guide to prevention of coronary heart disease prepared by the International Heart Task Force. ${ }^{14}$ This is a comprehensive guideline based on recommendations by the International Arteriosclerosis Society, The American Heart Association, The American College of Cardiology, The US National Heart Lung and Blood Institute, the Joint European Cardiovascular Societies, The World Heart Organization, and on the contents of the third report by the Adult Treatment Panel of the National Cholesterol Education Program; and 2) Specific and updated evidence-based guidelines for $\mathrm{CV}$ disease prevention in women. ${ }^{18}$

Patient records are stored on a central database server together with the application software accessible through a firewalled web server. Access to patient data is restricted to the physician and, exceptionally, to operators in anonymous epidemiological studies; in all other cases access is subordinated to explicit patient consent.

The physician, as a client, links to the database server using a secure internet protocol by means of a common 
computer, through a personal account for login and a common web browser as software interface, regardless of operating system, memory amount, and computer performance. All patient data sent on the Internet are coded using a secure protocol which safeguards the confidentiality of data transmission to the server. Client-server network layout to enter the software and patient's data is schematically depicted in Figure 1.

\section{Structure and function of the system}

Dynamic web pages allow the physician to run the software and then store, retrieve, compute, and show patient's data. In this way, all data and software are located on the server alone and no special client software is needed on the physicians' personal computer. The only requirement for the user is to know the server web address and to own a registered account. This web architecture permits direct access from any location, allowing the server administrator to monitor incoming connections. A further operative advantage is that updates and changes made to the software on the web server are immediately available to all other computers simultaneously.

\section{Patient record}

Events, diseases, parameters, qualitative data, and even diagnosis, indications, and messages are all coded in such a way as to better computerize data mining and parameter extraction. Table 1 shows the design scheme for patient's record. The data model is tree- structured, creating a userfriendly interface to record selectively and show patient data by means of nested multichoice frames (Figure 2). The data detail navigation can be stopped at any level and the detail frames and choice types are dynamically shown on the basis of the values of current data. This data-oriented model facilitates modification and upgrading of data without making changes to the software. From such data classification, an automatic final medical report may be

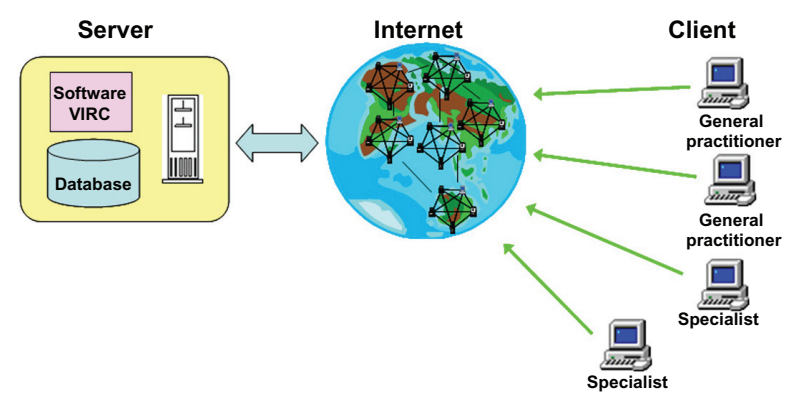

Figure I Client-server network layout to enter for software and patient data. created and, strictly for clinical purposes, be integrated with notes by the physician. The report composition (Figure 3) is obtained by referring to a clinical model of the patient record (main events, socio-economical factors, family and personal history, psychosocial events, physical activity, alcohol and dietary habits, atherosclerotic factors, kidney function, remote and actual pathologies, surgery interventions and hospitalization, symptoms and clinical signs, clinical-basal parameters, blood tests, ongoing therapies, referral for diagnostic tests). Other medical speciality areas can then be activated by simply integrating and updating the database with new patient data. A sharp separation exists between the data, structured together with the model, and the program, which uses tree-structured frames as a general user interface and which supply the engine for accessing and processing the data according to the model. This method enables the data, and even the model, to be upgraded easily and immediately, because the program need not be modified and the system can be implemented simply in another specialist area, changing only the data and the related model.

\section{Program}

The software allows the physician to select between first consultation and consecutive consultation, which avoids rewriting static patient data. Throughout follow-up, the physician can evaluate the evolution of the patient's health status through charts and trends, estimate changes in risk factors over time, evaluate success in risk reduction, and personalize policy against risk scores. Figure 4 shows the program navigation strategy following the user identification. At the first consultation, information on vital statistics, historical data, ethnic origin, education, past pathologies, as well as static data and social-economic and psychosocial factors, are collected by the physician or trained nurse; thereafter, the information will be automatically presented by the software at each consecutive consultation, with the possibility of if being updated. On the other hand, dynamic data, such as clinical parameters, actual diseases, therapy, and life-style, must be recorded at each consultation. Data and outcome estimates can then be printed. Figure 5 summarizes the program data flow with the screenshots showing the phases of the navigation.

Main events related to $\mathrm{CV}$ risk, such as heart attack, stroke, and other significant events can be recorded with timing of event. Subsequently the software promptly informs the physician of the stored event when he or she accesses the patient data. 
Table I Design scheme for patient record

\begin{tabular}{|c|c|c|}
\hline \multirow[t]{2}{*}{ Personal data } & \multirow[t]{2}{*}{ Frame } & First level details \\
\hline & & Name, birth date, sex, ethnic origin, country..... \\
\hline \multirow[t]{32}{*}{ Medical data } & Socio-economic factors & \\
\hline & Study degree & Primary, secondary, bachelor,.. \\
\hline & Professional activity & Employed, unemployed, retired,... \\
\hline & Main job occupation & Manual job, intellectual job, driver, manager,.. \\
\hline & Family history & \\
\hline & Relatives up to 2 nd degree & $\begin{array}{l}\mathrm{CV} \text { death/main } \mathrm{CV} \text { and non- } \mathrm{CV} \text { diseases and risk factors } \\
\text { (diabetes, hyperlipidemia.,...) }\end{array}$ \\
\hline & Personal history & \\
\hline & Sleep disorders & (trouble to sleep, early wake up,..) \\
\hline & Gynecologic/obstetric diseases & (polycystic ovary, pregnancy, diabetes,..) \\
\hline & Psychosocial factors & \\
\hline & Adverse life events & Self-reported personal/family/job/financial events/troubles \\
\hline & Psychological factors & Self-reported depression/stress/emotional factors/vitality \\
\hline & Lifestyle & \\
\hline & Physical activity & Amount/frequency/type (ie, hours per week,..) \\
\hline & Diet & Alcohol type (wine, beer, spirit), and amount per day \\
\hline & & Mediterranean diet adherence by a validated score \\
\hline & Individual CV risk factors & \\
\hline & $\begin{array}{l}\text { Primary factors (diabetes, obesity, } \\
\text { hyperlipidemia, hypertension,...) }\end{array}$ & Diabetes duration, insulin dependent or noninsulin-dependent diabetes,.. \\
\hline & Smoke & Type, amount, length (ie, pack-years),.. \\
\hline & Preclinic atherosclerosis & Left ventricular hypertrophy calcium score, intima media thickness... \\
\hline & Previous diseases & $\begin{array}{l}\text { Main remote pathologies: gastrointestinal, neurologic, pulmonary, } \\
\text { uro-genital, vascular diseases,... }\end{array}$ \\
\hline & Hospitalization & Number and type ( $\mathrm{CV}$ or non-CV) of admission during last year \\
\hline & Surgical/CV procedures & Main procedures: District (ie, aorta, coronary, renal), date of intervention... \\
\hline & Actual diseases & \\
\hline & CV pathologies & Type (ie, angina, ischemic card. dis., stoke), year, detail \\
\hline & Non CV pathologies & Type (ie, renal, endocrine, collagen diseases..) \\
\hline & Clinical-chemical parameters & \\
\hline & Basic vital signs & BP, HR, BMI, waist, hip circumference,... \\
\hline & Bio-humoral tests & Date, type and value \\
\hline & CV consultation & \\
\hline & Main symptoms and clinical signs & $\begin{array}{l}\text { Type and detail (ie, chest pain, dyspnea, vascular murmurs, } \\
\text { declive edema, NYHA class.,... }\end{array}$ \\
\hline & Ongoing therapies & Drug: international nonproprietary name, trade name, dosage \\
\hline
\end{tabular}

Abbreviations: BP, blood pressure; BMI, body mass index ; CV, cardiovascular; HR, heart rate; NYHA, New York Heart Association.

Nested multiple choice frames aid the physician in conducting the physical examination of the patient according to standard clinical good practice criteria to establish a standard model of clinical data description.

\section{Pilot study}

We set up a pilot study to define the feasibility and the clinical utility of the web-based program, and identify any glitches. To do this, we selected five doctors working in different cities of the Tuscany region who used computers in their daily practice.

Before starting the pilot study we arbitrarily defined the outcome as cut-offs that could be used to define the success or not of the pilot study, ie:
- cut-off for recruitment - at least 200 patients in 6 months and at least 40 patients for each recruiter

- cut-off for feasibility - glitches $<10 \%$ during consultation average consultation time $<20$ minutes in $>80 \%$ of consultations

- cut-off for clinical powerful - evidence for at least 2 concomitant emerging $\mathrm{CV}$ risk factors in $>30 \%$ of subjects.

\section{Results}

The medical layout and main fields are shown in Figure 6. By selecting the button and list icons further details can be obtained in subsequent frames. 




Figure 2 Example of consequent frames in a multichoice answer used in the patient record.

\section{Technical system}

The software enables the physician to identify the patient's $\mathrm{CV}$ state through several computing and referring instruments, as listed below:

- Computed CV risk factor: Framingham, Procam, Progetto Cuore indexes ${ }^{19,20,27}$ are promptly computable to supply absolute, relative, and baseline 10 -year CV risk of CV events. The software allows changes to one or all of the patient's modifiable parameter values (eg, cholesterol, pressure, smoking) to predict the new (ie, relative) CV risk factor (Figure 7).

- The program considers all the algorithms: a) the global risk (absolute) related to the different parameters utilized

Report of Mrs RL born on 02 February 1945

Date of consultation on 21 February 2008 at 05:28 pm

Family history: mother: dyslipidemia, ischemic cardiopathy

Smoking habit: 15 cigarettes per day for 10 years

No physical activity

Diet score: 18 (moderate adherence to mediterranean diet: male $>25$, female $>27$ )

Individual CV risk factors: dyslipidemia

Kidney function (Cockroft-Gault) $40.4 \mathrm{~mL} / \mathrm{min}$ normalized to body surface

Basal parameters: BP 130/70 mmHg, HR 70 bpm, sinus rhythm, weight $77 \mathrm{Kg}$,

Height $160 \mathrm{~cm}$, BMI 30.1, waist circumference $93 \mathrm{~cm}$, hip circumference $106 \mathrm{~cm}$ Waist/hip ratio: 0.88

Blood test (12/02/2008): HDL $40 \mathrm{mg} / \mathrm{dL}, \mathrm{LDL} 170 \mathrm{mg} / \mathrm{dl}$, total cholesterol $250 \mathrm{mg} / \mathrm{dl}$

Triglycerides $200 \mathrm{mg} / \mathrm{dL}$, creatinine $1 \mathrm{mg} / \mathrm{dL}$, glycemia $85 \mathrm{mg} / \mathrm{dL}$

$\mathrm{CV}$ risk at 10 years:

Method Global Base

FRAMINGHAM $\quad 19 \% \quad 5.1 \%$

PROCAM $\quad 8.6 \% \quad 1 \%$

PROGETTO CUORE $\quad 5 \%-10 \% \quad<5 \%$

Objectives:

1) to increase physical activity at 30 min per day;

2) to stop smoking;

3) to reduce $\mathrm{BMI}$ to $<25$ and waist circumference $<80 \mathrm{~cm}$;

4) to balance dietary intake (diet score $>27$ );

5) to reduce $\mathrm{LDL}<130 \mathrm{mg} / \mathrm{dL}$ and $\mathrm{TGL}<150 \mathrm{mg} / \mathrm{dL}$

Figure 3 Example of the program's indications for a typical patient.

Abbreviations: BP, blood pressure; BMI, body mass index; CV, cardiovascular; HDL, high-density lipoprotein; LDL, low-density lipoprotein; TGL, triglycerides.

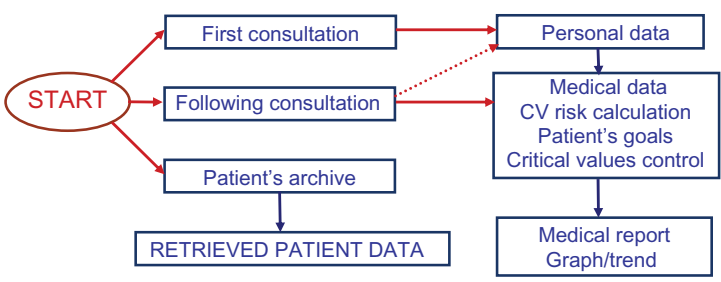

Figure 4 Navigation strategy.

for each algorithm; b) the basic risk (baseline) deduced from static (ie, sex and age) parameters from the patient and by including all the modifiable parameters as normal; c) the hypothetic, expected risk (relative) by starting from the parameters measured for the patient and by assuming the normalization of one or more parameters.

- Patient objectives: Figure 3 shows a typical example of data collected for a 63-year-old, smoker, normotensive,

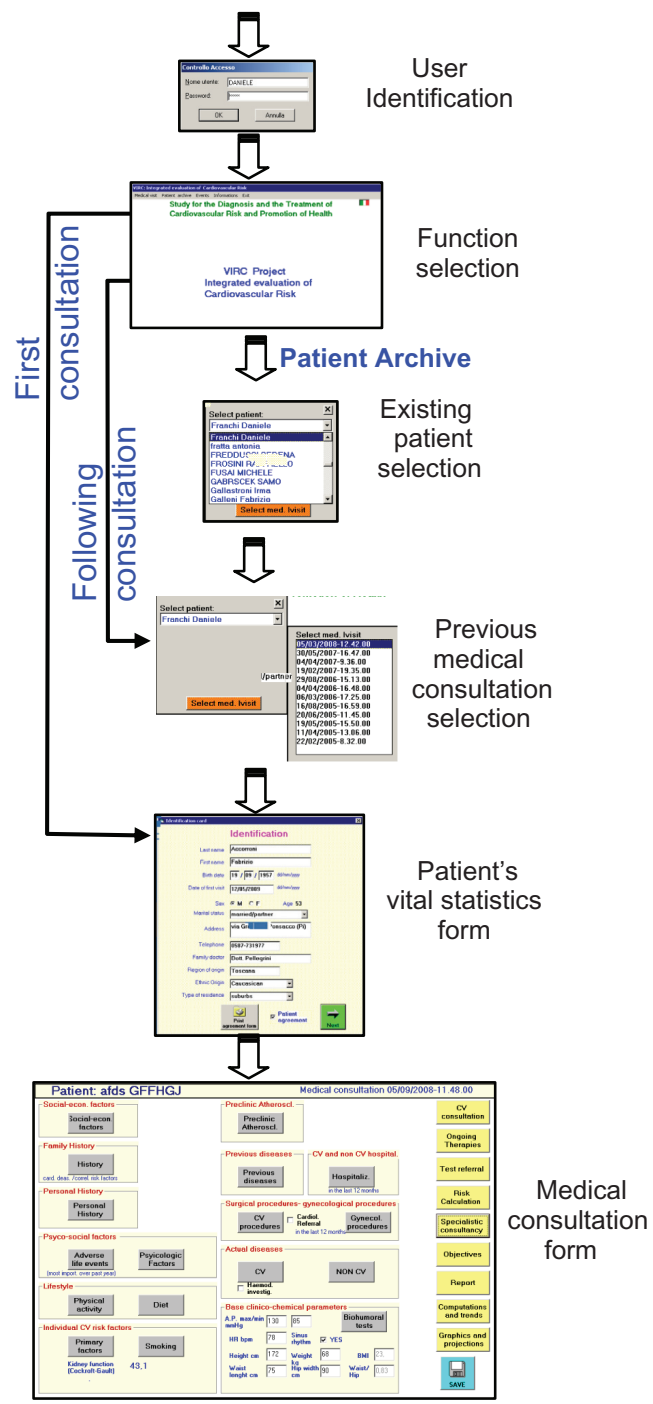

Figure 5 Program data flow. 


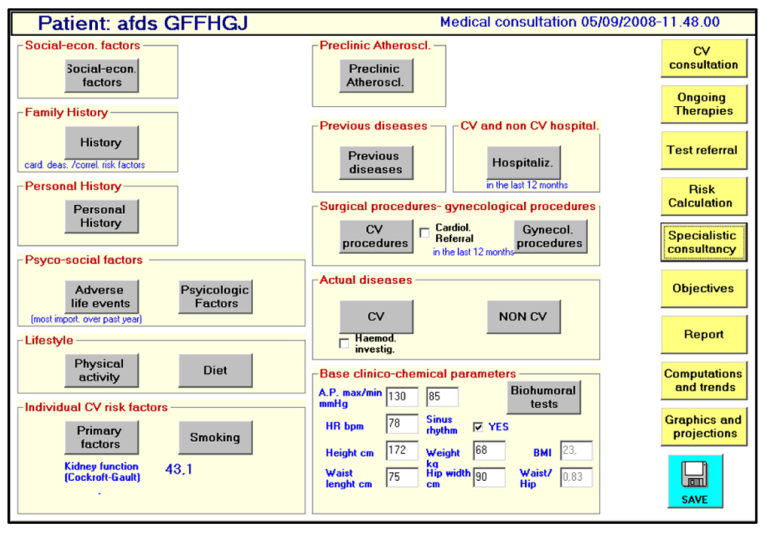

Figure 6 Synoptic medical layout.

hyperlipidemic female, with no physical activity or Mediterranean diet. The quantitative values of prescriptions, computed for $\mathrm{CV}$ risk target, can be adjusted by the physician in agreement with the patient in order to establish together a personalized therapeutic path that the patient could indeed follow in his or her daily life. The effect of patient compliance must be evaluated by the physician at the next consultation and, if necessary, discussed again.


Figure 7 Example of absolute, baseline and predicted CV risk as computed by the program.
- Multiparametric/agreed and predicted graph/trends. Temporal trends of different kinds of the patient's multiple data arising from actual and previous consultations can be shown on a table or on a plot underlying the relationships among different parameters. Moreover, each single parameter is plotted in a graph as real values recorded at consultations together with the target value (obtained from guidelines and the value the physician agreed with the patient during the objectives definition phase (microgoals). This kind of plot allows the physician (and the patient) to evaluate the effectiveness of a personalized therapeutic path (Figure 8).

- Critical values: To better characterize the patient's clinical status, the software is able to present evidence for all clinical parameters that can be considered critical according to international recommendations..$^{14,18,22}$ The software takes into account the comorbidity effects (eg, diabetes, hypertension, hyperlipidemia) that change the target values derived from single pathology guidelines. ${ }^{14}$ This suggestion aims to reduce possible omissions or underestimations of the patient data by the physician, leaving them free to make their own evaluation.

- Medical report: At the end of the consultation, the structured data are automatically summarized in natural text in a report like the typical medical report, which can be stored or printed for further consultation as a unique document describing the consultation. The physician might change it or update it in free text, which is not computable for epidemiological analysis.

\section{Pilot study validation}

The main data derived from the pilot study are reported in Tables 3-7. Table 2 shows the main demographic data for

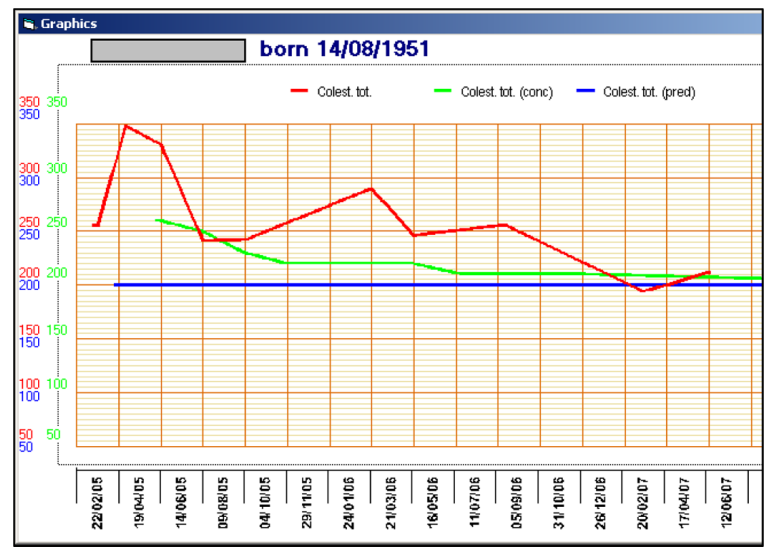

Figure 8 Example of agreed and predicted graph (red: measured, green: agreed by the doctor, blue: predicted by guidelines). 
Table 2 Demographic information about the sample used for the pilot study

\begin{tabular}{llll}
\hline & GP $(\mathbf{n}=\mathbf{2})$ & Specialist $(\mathbf{n}=\mathbf{3})$ & Total \\
\hline Recruited patients & 163 & 131 & 294 \\
Male/female & $96 / 67$ & $60 / 71$ & 294 \\
Age & $59 \pm 10$ & $62 \pm 15$ & $60 \pm 12$ \\
BMI & $27.1 \pm 4$ & $25.3 \pm 4$ & $26.2 \pm 4$ \\
\hline
\end{tabular}

Abbreviation: GP, general practitioner.

the sample utilized in the pilot study. Figure 9 depicts the geographical distribution of the doctors involved in pilot study. A total of 294 patients was recruited in 6 months and only 1 out of the 5 doctors did not reach the 40 recruitments cut-off (Table 3).

- Feasibility: Global time to collect data at first consultation was $13 \pm 11$ minutes which declined to $8 \pm 7$ minutes at the subsequent consultation. Of first consultations, $16 \%$ were more the 20 minutes (Table 4).

- Glitches: Technical glitches, such as trouble entering server, were observed in only $2 \%$ of cases. Very occasionally doctors were unable to find a suitable choice among program proposals (ie, heavy drinking only once a week).

- Clinical validation: Table 5 reports the percentage of positive primary and additional risk factors in the studied population. Table 6 reports the difference in CV risk estimate by different algorithms according to the severity of computed risk. In $48.2 \%$ of cases (Table 7) the program revealed 2 or more parameters out of the main guideline indications and gives specific clinical suggestions to return parameters to target values. As shown in Table 7, the CV risk factor numbers of the studied population are independent from sex and age: more than $80 \%$ had at least $1 \mathrm{CV}$ risk factor and almost half had $2 \mathrm{CV}$ risk factors. Notably, additional CV risk factors (eg, obesity and mental stress) were highly represented in the population (Table 5). Also, more than $44 \%$ of cases/patients showed at least 2 or more additional CV risk factors.

Table 3 Consultation statistics for the pilot study

\begin{tabular}{llll}
\hline Doctors & \multicolumn{3}{l}{ Patient number } \\
\cline { 2 - 4 } & First & Subseq. & Total \\
\hline Doct. I & 63 & 3 & 66 \\
Doct. 2 & 21 & 0 & 21 \\
Doct. 3 & 43 & 0 & 43 \\
Doct. 4 & 67 & 12 & 79 \\
Doct. 5 & 100 & 6 & 106 \\
Total & $\mathbf{2 9 4}$ & $\mathbf{2 0}$ & $\mathbf{3 1 5}$ \\
\hline
\end{tabular}

Table 4 Global time to collect data at first and subsequent consultation

\begin{tabular}{lll}
\hline $\begin{array}{l}\text { Consultation time } \\
\text { (minutes) }\end{array}$ & First & Subsequent \\
\hline$<5$ & $12 \%$ & $36 \%$ \\
From 5 to 10 & $37 \%$ & $29 \%$ \\
From 10 to 15 & $28 \%$ & $21 \%$ \\
From 15 to 20 & $9 \%$ & $7 \%$ \\
From 20 to 25 & $4 \%$ & $0 \%$ \\
From 25 to 30 & $5 \%$ & $7 \%$ \\
$>30$ & $7 \%$ & $0 \%$ \\
Mean $( \pm S D)$ & $13 \pm$ II & $\mathbf{8} \pm \mathbf{7}$ \\
\hline
\end{tabular}

\section{Discussion}

The management of primary and secondary $\mathrm{CV}$ prevention is increasingly complex due to i) its intrinsic multidisciplinary nature and ii) the rapid growth of pathophysiological knowledge in the field. ${ }^{6,12,14,15,23-25} \mathrm{~A}$ well-designed computer based program might thus represent a useful tool to assist physicians during their daily clinical practice. ${ }^{26}$ The main advantages over the currently available computerized systems to assess CV risk ${ }^{19,20,26,27}$ are the result of the web-based architecture. First, no software needs to be installed on the doctor's computer and the patient data between client and server does not need upgrading because all data and software reside on the server; only a low download speed internet link is required, since the amount of data transferred is very low. Second, all patient data on the server are updated at all times, and are available worldwide at any time; changes in the program and upgrade of guidelines are immediately usable.

In current clinical practice doctors separate the $\mathrm{CV}$ risk evaluation from the routine consultation, even if they use an electronic patient record program; the purpose of the proposed program is to combine these two phases to avoid data replication.

Table 5 Percentage of primary and additional cardiovascular (CV) risk factors (RF) found in the pilot study

\begin{tabular}{lll}
\hline Primary CV RF & \% male & \% female \\
\hline Hypercholesterolemia & 62 & 63 \\
Hypertriglyceridemia & 42 & 26 \\
Hypertension & 25 & 14 \\
Diabetes & 9 & 6 \\
Smoking habit & 14 & 10 \\
Additional RF & & \\
Overweight & 19 & 18 \\
Obesity & 48 & 26 \\
No Mediterranean diet & 68 & 86 \\
No physical activity & 55 & 66 \\
Mental stress & 38 & 53 \\
\hline
\end{tabular}


Table 6 Normalized difference in cardiovascular (CV) risk factor computation by different algorithms according to the severity of computed risk

\begin{tabular}{llll}
\hline CV risk $\%$ & Framingham & Procam & Prog. Cuore \\
\hline$<5 \%$ & $26 \%$ & $55 \%$ & $54 \%$ \\
$5 \%-10 \%$ & $25 \%$ & $12 \%$ & $22 \%$ \\
$10 \%-15 \%$ & $19 \%$ & $6 \%$ & $15 \%$ \\
$15 \%-20 \%$ & $9 \%$ & $5 \%$ & $4 \%$ \\
$20 \%-25 \%$ & $6 \%$ & $4 \%$ & $3 \%$ \\
$25 \%-30 \%$ & $3 \%$ & $5 \%$ & $2 \%$ \\
$>30 \%$ & $11 \%$ & $13 \%$ & $2 \%$ \\
\hline
\end{tabular}

A real problem arises when doctors already use their own electronic patient record programs. A specific middleware should be developed to integrate both databases and even a data entry interface so that doctors do not input the same data twice.

The major advantages of the computer-based approach described here are:

- Simple and usable data acquisition that is as comprehensive as possible in terms of both well-known and less-known, but emerging, CV risk factors including psychosocial and behavioral factors. In particular, the new computer program is intended to evaluate a large number of parameters instead of the few used to define algorithms of the principal formulae (eg, Framingham, Procam, Progetto Cuore) $)^{19,20,27}$ to calculate absolute and relative $\mathrm{CV}$ risk. The proposed web-based $\mathrm{CV}$ risk assessment program, compared with similar existing $\mathrm{CV}$ risk assessment tools, also enables additional $\mathrm{CV}$ risk factors (eg, lifestyle, psychological, stress) and greater details on smoking habits to be collected in a structured manner. ${ }^{19,20,26,27}$ The use of a computer program enables the doctor to automatically retrieve from the database data on the patient's previous consultation, inputting only new values, such as blood pressure values, weight, and therefore reducing check-up time. Moreover, adoption of hardware/software instruments as data entry by means of web forms or optical scanning of typewritten sheet might further simplify and speed up program use.

- The program clearly displays and quantifies the comparison between the $\mathrm{CV}$ risk indexes of risk measured for the patient and those measured for an age- and sexmatched reference population with indexes accepted as normal. Notably, the program can be used during a consultation to allow the patient to immediately understand the health benefits predicted with changes in lifestyle (eg, stopping smoking or drug abuse, or antihypertensive and/ or lowering lipid treatment). Through the current configuration the program automatically shows both physician and patient the entity of risk reduction by a specific change in one or more of the abnormal risk factors.

- The program is highly flexible in its potential use and application. One part can be used for statistical and epidemiological purposes (ie, definition of a new chart of CV risk for the population under surveillance) and another can be used to explore and collect additional clinical data to improve patient adherence to therapeutic strategy. ${ }^{28}$ It is noteworthy that slightly reducing the weight of risk factors can be more beneficial than a greatly reducing a single risk factor. ${ }^{14} \mathrm{~A}$ target level of risk reduction might be achieved by several different routes, and the patient could participate in deciding which route to follow. The program may also help the doctor to improve personal feedback and monitoring of data of interest during treatment by producing graphical trends or tabulations of single or multiple parameters over time.

- The program has a substantial component of automated checking systems that reduce the risk of diagnostic omissions and identifies critical laboratory values according to international guidelines. ${ }^{22}$ Even more

Table 7 Percentage of patients with principal cardiovascular (CV) risk factors (ie, blood pressure, low-density lipoprotein cholesterol, high-density lipoprotein cholesterol, triglycerides, glycemia, smoke) from the main guideline indications on the basis of the three adopted algorithms

\begin{tabular}{|c|c|c|c|c|c|c|}
\hline \multirow{2}{*}{$\begin{array}{l}\text { Number } \\
\text { CV risk factors }\end{array}$} & \multicolumn{3}{|c|}{ Male } & \multicolumn{3}{|c|}{ Female } \\
\hline & $\%$ & $\%$ cum. & Mean age (years) & $\%$ & $\%$ cum. & Mean age (years) \\
\hline 0 & $19 \%$ & & 57 & $17 \%$ & & 60 \\
\hline I & $35 \%$ & $81 \%$ & 64 & $32 \%$ & $83 \%$ & 61 \\
\hline 2 & $29 \%$ & $46 \%$ & 60 & $23 \%$ & $51 \%$ & 58 \\
\hline 3 & $13 \%$ & $17 \%$ & 59 & $16 \%$ & $27 \%$ & 63 \\
\hline 4 & $3 \%$ & $4 \%$ & 75 & $10 \%$ & $11 \%$ & 58 \\
\hline 5 & $1 \%$ & $1 \%$ & 63 & $1 \%$ & $1 \%$ & 67 \\
\hline 6 & $0 \%$ & $0 \%$ & & $0 \%$ & $0 \%$ & \\
\hline 7 & $0 \%$ & $0 \%$ & & $0 \%$ & $0 \%$ & \\
\hline
\end{tabular}

Abbreviation: cum., cumulative. 

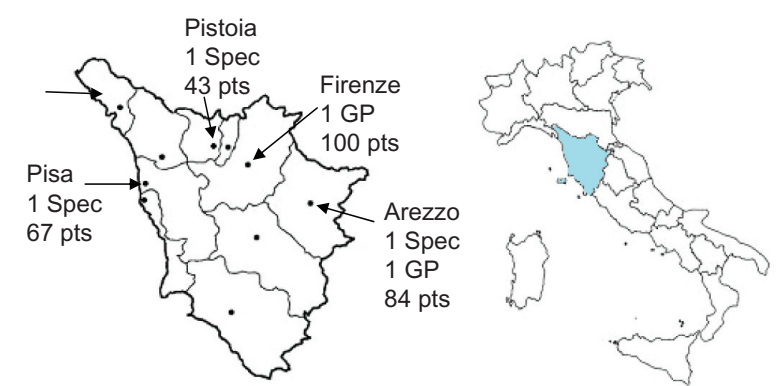

Figure 9 Regional distribution of patients and doctors (general practitioner, GP and specialist, Spec) in the pilot study.

important is the possibility during a consultation to automatically compare the chosen therapeutic program with the more reliable guidelines or international recommendation in the field. In an era of evidencebased medicine this represents a fundamental tool to convince both doctor and patient of the importance of the program.

- Finally three major comments can be made about the pilot clinical study:

a. The new tool is a feasible and practical way of computing $\mathrm{CV}$ risk in clinical practice within an acceptable time frame (Table 4);

b. The large variability observed when adopting different algorithms to compute CV risk (Table 6) in the same subject suggests the need to implement a new, specific algorithm for each population under study;

c. The high percentage of more than one additional CV risk factor (eg, mental stress, obesity, physical activity) in $44 \%$ of patients suggests the need for further systematic evaluation of the relative weight of these parameters when computing CV risk.

\section{Conclusion}

The system we propose represents a feasible and flexible tool for clinical management of patients and epidemiological research.

Moreover, the acquisition of structured data enables later queries during epidemiological studies. A new algorithm based on primary and emerging $\mathrm{CV}$ risk factors could be provided for the specific population under evaluation after collection of a significant amount of patient data by the present web-based system. Because the software is server-based, upgrades are immediately available to all users.

\section{Summary}

- The classical algorithms used for CV risk assessment do not take into account several emerging $\mathrm{CV}$ risk factors
- Very often, CV risk indexes are computed from different populations without considering the specific features of the actual population

- Usually, CV risk estimates and electronic medical records are separate

- The access from common computers is easy despite operating system and application software

- A centralized medical database is available that enables the patient to be followed up wherever they are; authorized sharing of patient clinical status between different doctors and specialists

- Real time update/upgrades of medical guidelines, patient data, and system

- Standardized medical support for patient medical consultation

- Personalized therapy and lifestyle changes with patient agreement

\section{Authorship}

Daniele Franchi: software and database design, article drafting, final version approval. Davide Cini: server, network system, and web design, article drafting, final version approval.

Giorgio Iervasi: clinical dataset and medical knowledge design, article drafting, final version approval.

\section{Acknowledgments}

We gratefully acknowledge Drs L Ghiadoni, G Testi, G Frigerio, R Giovannetti, F Gabriele (FATO Project Regione Toscana - Direzione Generale Diritto alla Salute 2009-2010) for providing their support in the acquisition of pilot clinical data.

We would like to thank Laura Mazza for her secretarial assistance.

This work has been supported by a Tuscany Region Grant (Assignment n626 03/09/2007) and by FORMED Onlus.

\section{Disclosure}

The authors report no conflicts of interest.

\section{References}

1. De Backer G, Ambrosioni E, Borch-Johnsen K, et al. European guidelines on cardiovascular disease prevention in clinical practice. Eur J Cardiovasc Prev Rehabil. 2003;10:S1-S78.

2. Sidney C, Smith Jr, Allen J, et al. AHA/ACC Guidelines for secondary prevention for patients with coronary and other atherosclerotic vascular disease: 2006 update. J Am Coll Cardiol. 2006;47:2130-2139.

3. Holmes JS, Arispe IE, Moy E. Heart disease and prevention: race and age differences in heart disease, prevention, treatment and mortality. Med Care. 2005;43:I33-I41. 
4. Smith SC Jr, Blair SN, Bonow RO, et al. AHA/ACC guidelines for preventing heart attack and death in patients with atherosclerotic cardiovascular disease: 2001 update: A statement for healthcare professionals from the American Heart Association and the American College of Cardiology. Circulation. 2001;104:1577-1579.

5. Hopkins PN, Williams RR. Identification and relative weight of cardiovascular risk factors. Cardiol Clin. 1986;4:3-31.

6. Rosengren A, Hawken S, Ounpuu S, et al. Association of psychosocial risk factors with risk of acute myocardial infarction in 11119 cases and 13648 controls from 52 countries (the INTERHEART study): case-control study. Lancet. 2004;364:953-962.

7. Rozanski A, Blumenthal JA, Davidson KW, et al. The epidemiology, pathophysiology and management of psychosocial risk factors in cardiac practice. The emerging field of behavioral cardiology. J Am Coll of Cardiol. 2005;45:637-651.

8. Scheier MF, Matthews A, Owens JF, et al. Optimism and rehospitalization after coronary artery bypass graft surgery. Arch Intern Med. 1999; 159:829-835.

9. Scientific Exchange. Consensus statement dietary fat, the mediterranean diet and lifelong good health. 2000 International conference on the mediterranean diet. www.chd taskforce.de//2000consensusstatement/\# contents. Royal College of Physicians, London, January 13-14, 2000.

10. Sowers JR. Obesity as a cardiovascular risk factor. Am J Med. 2003; $115: 37 \mathrm{~S}-41 \mathrm{~S}$.

11. Taylor DJ, Lichstein KL, Durrence HH. Insomnia as a health risk factor. Behav Sleep Med. 2003;1:227-247.

12. Yusuf S, Hawken S, Ounpuu S, et al. Effect of potentially modifiable risk factors associated with myocardial infarction in 52 countries (The INTERHEART study): case-control study. Lancet. 2004; 364:937-952.

13. Ritz E. Total cardiovascular risk management. Am J Cardiol. 2007; 100:53J-60J.

14. Assmann G, Buyken A, Cullen P, Schulte H, von Eckardstein A, Wahrburg U. Pocket guide to prevention of coronary heart disease. International Task Force for Prevention of Coronary Heart Disease. http://www.chd-taskforce.com/pocketpc_, Jan 2003:1-128.

15. Kostis JB. A new approach to primary prevention of cardiovascular disease. Am J Med. 2007;120:746-747.

16. Erhardt LR. Managing cardiovascular risk: reality vs perception. Eur Heart J Suppl. 2005; 7:L11-L15.
17. Sheerin I, Hamilton G, Humphrey A, Scragg A, et al. Issues in the assessment of cardiovascular risk in selected general practices in Canterbury, New Zealand. NZ Med J. 2007;120:U2714.

18. Mosca L, Banka CL, Benjamin EJ, et al. Evidence-based guidelines for cardiovascular disease prevention in women: 2007 update. Circulation. 2007;115(11):1481-1501.

19. Menotti A, Lanti M, Puddu PE, et al. The risk functions incorporated in riscard 2002: a software for the prediction of cardiovascular risk in the general population based on Italian data. Ital Heart J. 2002; 3:114-121.

20. Vrentzos GE, Papadakis JA, Ganotakis ES, et al. Predicting coronary heart disease risk using the Framingham and PROCAM equations in dyslipidaemic patients without overt vascular disease. Int J Clin Pract. 2007:1643-1653.

21. Panagiotakos D, Pitsavos C, Stefanidis C. Dietary patterns: A Mediterranean diet score and its relation to clinical and biological markers of cardiovascular disease risk. Nutr Met Cardiovas Diss. 2006; 16:559-568.

22. Howanitz P, Steindel SJ, Heard NV. Laboratory critical values policies and procedures- Arch Pathol Lab Med. 2002;126:663-669.

23. Leineweber C, Kecklund G, Akerstedt T, et al. Snoring and the metabolic syndrome in women. Sleep Med. 2003;4:531-536.

24. Leineweber C, Kecklund G, Janszky I, et al. Poor sleep increases the prospecitve risk for recurrent events in middle-aged women with coronary disease. The Stockholm female coronary risk study. J Psychosom Res. 2003;54:121-127.

25. Leineweber C, Kecklund G, Janszky I, et al. Snoring and progression of coronary artery disease: The Stockholm female coronary angiography study. Sleep Med. 2004;27:1344-1349.

26. Hingorani AD, Vallance P. A simple computer program for guiding management of cardiovascular risk factors and prescribing. BMJ. 1999; 318:101-105.

27. Assmann G, Cullen P, Schulte H. Simple scoring scheme for calculating the risk of acute coronary events based on the 10-year follow-up of the prospective cardiovascular munster (PROCAM) study. Circulation. 2002;105:310-315.

28. Munger MA, van Tassell BW, LaFleur J. Medication nonadherence: an unrecognized cardiovascular risk factor. Med Gen Med. 2007;9:58.
Therapeutics and Clinical Risk Management

\section{Publish your work in this journal}

Therapeutics and Clinical Risk Management is an international, peerreviewed journal of clinical therapeutics and risk management, focusing on concise rapid reporting of clinical studies in all therapeutic areas, outcomes, safety, and programs for the effective, safe, and sustained use of medicines. This journal is indexed on PubMed Central, CAS,

\section{Dovepress}

EMBase, Scopus and the Elsevier Bibliographic databases. The manuscript management system is completely online and includes a very quick and fair peer-review system, which is all easy to use. Visit http://www.dovepress.com/testimonials.php to read real quotes from published authors. 